\title{
Tumor of orbit
}

\section{Tumor orbitário}

Mirjana A. Janicijevic-Petrovic ${ }^{1}$, Tatjana S. Sarenac-Vulovic ${ }^{1}$, Katarina M. Janicijevic ${ }^{2}$, Dejan D. Vulovic ${ }^{2}$, Dragan I. Vujic ${ }^{3}$

\begin{abstract}
The cavernous hemangiomas are the most common intra orbital tumors found in adults of the middle age. Although histological benign, they can encroach on intra orbital or the adjacent structures (optic nerve) and be considered anatomically or positional malignant. We present a case report of orbital cavernous hemangioma of right orbit in young women after pregnancy, from Topola near Kragujevac (Central Serbia) with visual compromise and it's by trans-nasal endoscopic surgical management. Our patient was controlled and treated with the symptomatic therapy, topical therapy with artificial tears and surgical treatment. Our patient has optimal visual acuity of affected right eye after surgical treatment of orbital tumor. Surgical treatment of symptomatic orbital cavernous hemangioma is safe and effective, so that the cosmetic results are the important parameter to evaluate the clinical outcome.
\end{abstract}

Keywords: Cavernous hemangioma/diagnosis; Cavernous hemangioma/surgery; Orbit/pathology; Case reports

\section{RESUMO}

Os hemangiomas cavernosos são os tumores intra-orbitais mais comuns encontrados em adultos de meia-idade. Embora histológico benigno, eles podem invadir orbital intra ou as estruturas adjacentes (nervo óptico) e ser considerado anatomicamente ou posicional maligno. Apresentamos um relato de caso de hemangioma cavernoso orbital da órbita direita em mulheres jovens após a gravidez, a partir de Topola perto Kragujevac (Central Sérvia) com comprometimento visual e é por tratamento cirúrgico endoscópico trans-nasal. A paciente foi controlado e tratado com a terapia, terapia tópica sintomático de lágrimas artificiais e tratamento cirúrgico. Nosso paciente tem acuidade visual ideal do olho direito afetada após o tratamento cirúrgico de tumor orbital. O tratamento cirúrgico do sintomático hemangioma cavernoso orbital é segura e eficaz, de modo que os resultados cosméticos são o parâmetro importante para avaliar o resultado clínico.

Descritores: Hemagnioma cavernoso/diagnostic; Hemangioma cavernoso/cirurgia; Orbita/patoogia; Relatos de casos

\footnotetext{
${ }^{1}$ Clinic of Ophthalmology, Clinical Centre in Kragujevac, Serbia.

${ }^{2}$ Faculty Medical Sciences, University of Kragujevac, Serbia.

${ }^{3}$ State University of Novi Pazar, Serbia.
}

The authors declare no conflicts of interest

Received for publication: 4/4/2013 - Accepted for publication: 27/11/2013 


\section{INTRODUCTION}

$\mathbf{O}$ rbit tumor occurs in middle-aged women, and has its peak incidence in early middle age. The capillary and cavernous hemangiomas are the most common vascular tumors and are classified separately because of distinct clinical and pathologic differences ${ }^{1}$.

Visual disability results from a high degree of relative hyperopia or from optic nerve compression. Relative hyperopia may persist, in spite of complete removal of tumor. The pattern of choroidal folds generally reflected the location of the tumor within the orbit ${ }^{2}$. B-ultrasound and MRI in combination with clinical manifestations facilitated the diagnosis and orientation of orbital cavernous hemangiomas ${ }^{3}$.

The most patients underwent B-ultrasound and surgical exploratory procedures. The most of tumors are unilateral and can increase intra orbital volume with a resultant the mass effect. Complete excision is usually possible and surgical morbidity is low. The morbidity associated with orbital cavernous hemangioma is the threat of compressive optic neuropathy, extra ocular muscle dysfunction and cosmetic disfigurement ${ }^{4}$.

\section{Case report}

A 28 years old female presented with two months history of a progressive right visual loss, that had worsened during the last pregnant in 2012.

She presents with ptosis and eye movement limitation of right eye, about two years ago.

After a complete ophthalmologic evaluation, she performed the perimetry that showed severe, peripheral decrease of visual field sensitivity, as incomplete hemianopsy.

Ultrasonography and MRI showed intra orbital mass that filled up homogeneously at the right orbital apex, compressing the orbital nerve and with close relationship with extra ocular muscles.

Visual acuity of the right eye was 0.1 with correction, and 1.0 with correction of the left eye (hypermetropio/anisometropio) by Snellen's test. On examination, ptosis of $4 \mathrm{~mm}$ was noted in

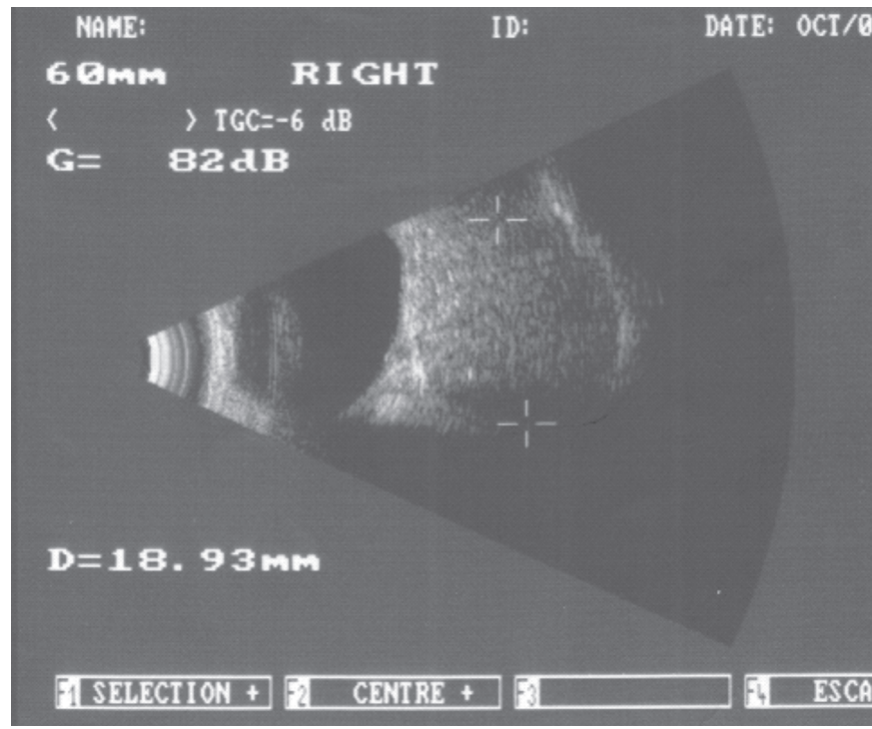

Figure 1. Ultrasonography of the right eye (standardized B-scan) showed well circumscribed intraconal mass in the right orbit, as vascular tumor and $\mathrm{R}=19 \mathrm{~mm}$

the right eye. Intraocular pressures (Goldman's tonometry) were regular (pre and post operative). Hertel's measurement (by egzoophthalmometry) was $24 \mathrm{~mm}$ on the right eye and $22 \mathrm{~mm}$ on the left eye (both-preoperative) and the less-postoperative was $22 \mathrm{~mm}$ on the right eye. The test of double vision was regular always. Slit examination of the both eye was regular. Fundus examination of right eye indicated for the choroidal folds without clear margin of the right optic nerve. Indirect ophthalmoscopy of left eye showed correct clinical state. Ultrasonography showed retro bulbar marked regular and oval formation 20x19mm, near of the right optic nerve, figure 1.

Perymetry (Humphrey-perimetry tests) showed the specific scotoma - hemianopsy with transitory field compromise, with the best results after surgical treatment, figure 2 .

MRI showed the hyperdense, retro bulbar, oval, intraconal
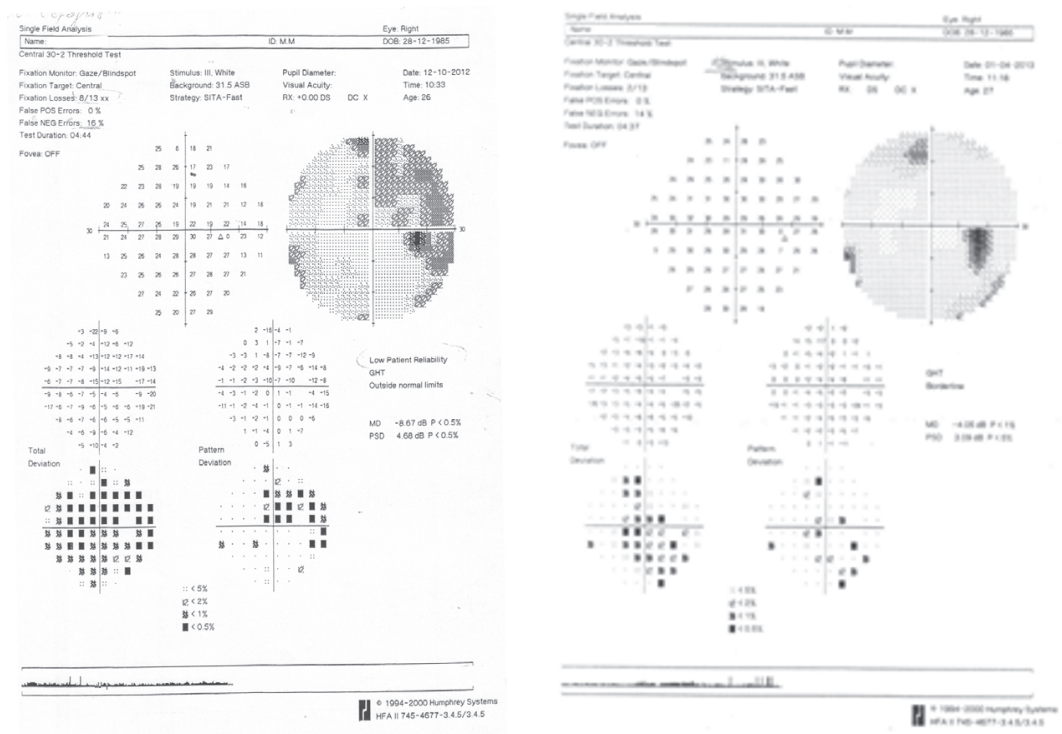

Figure 2. The perimetry tests of the right eye with orbit tumor and the scotoma incomplete hemianopsy (before and after surgical treatment - as the best results) 


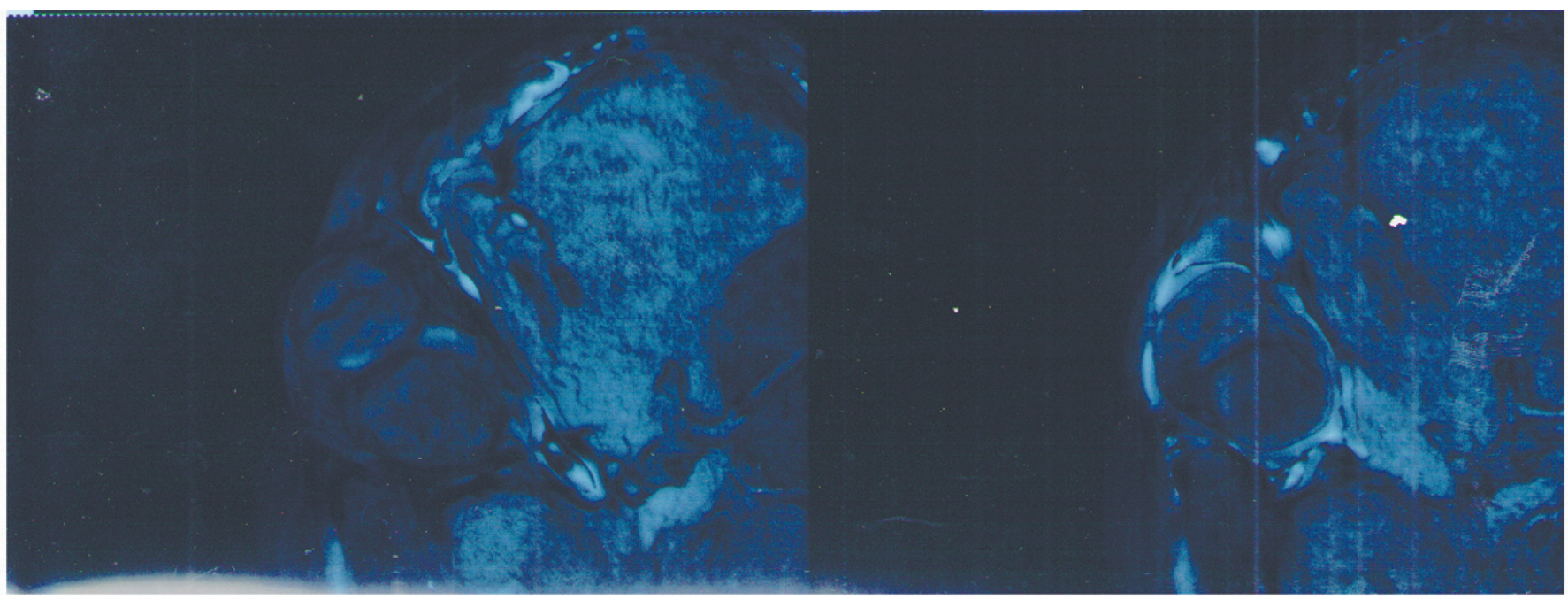

Figure 3. MRI examination of the right orbit with cavernous hemangioma

mass in the right orbit, located in the inferior temporal quadrant. This formation $(21 \times 20 \mathrm{~mm})$ was as tissue, clear margin, and with compression of the neurovascular elements of the right orbit, figure 3 .

Clinical indication for MRI was act to consultation of neurosurgical and plastic doctors.

Operation was done in general anesthesia in Belgrade as a low-risk procedure.

Hystopathological test was showed the benign lesion of cavernous subtype (large anastomosing vascular spaces observed filled of blood, separated by fibrous stroma) and the pathological diagnosis was the cavernous hemangioma (from the Belgrade).

The adjuvant therapy during hospitalization was the symptomatic therapy (steroid drugs, antibiotics) and topical therapy with artificial tears.

\section{Discussion}

The most orbital hemangiomas require no intervention, but especially when there is visual compromise, orbit surgery is needed as treatment, but MRI evidence of intralesional hemorrhage was confirmed by histopathology in diagnosis, as authors known ${ }^{1}$.

Indications for surgical therapy were visual impairment, progressive unilateral ptosis, diplopia and orbital pain clearly related to orbital cavernoma. The hemangiomas are found between extra ocular muscles and optic nerve within the intraconal place, classically within medial aspect of the orbit and it leads to axial exophthalmia, was in our case ${ }^{5}$.

They are approached through an upper eyelid or a transcaruncular based medial orbitotomy. Gentle dissection allows for en-bloc removal after all vessels have been identified and cauterized with bipolar cautery, that the resection via these approaches can be considered as a low-risk procedure ${ }^{6}$.

Friberg et al., speak that comparison with uninvolved fellow eyes showed that preoperative refractive errors were usually shifted toward hyperopia with intraconal tumor, whereas extraconal tumors were typically associated with higher astigmatic errors on involved side, as authors showed ${ }^{2}$.

The vascular tumors of the orbit include capillary heman- gioma, cavernous hemangioma, hemolymphangioma, hemangiopericytoma (the rare tumor), and we had the cavernous hemangioma ${ }^{7}$.

Transnasal endoscopic resection of intra orbital tumors is feasible and may offer advantages when compared to traditional approaches. It is paramount to have specialized instruments such as long hand piece drills, good camera systems, and long bipolar forceps, as well as an experienced endoscopic surgeon, to control vascular lesions and potential life threatening complications, as was the surgical treatment in our patient $t^{8,9}$. The endoscopic transnasal approach is safe, effective and less invasive therapeutic modality for removal of lesions extending from inferomedial part of the left orbital apex to pterygopalatine fossa. With appropriate patient selection, this approach improves access and visualization, and it enables performance of operative procedures with less risk than conventional microscopic transcranial or transfacial approaches ${ }^{8,9}$.

Wiegand et al., say that the histopathologic slides were evaluated and additional immunohistochemical stains were done, if necessary to get the correct diagnosis, as we got from the Belgrade ${ }^{3}$.

Visual function and cosmetic result are main parameters to evaluate clinical outcome. Surgical approach and dissection technique are crucial in determining visual outcome, as in our case report ${ }^{10}$.

Rootman et al., reported on use of fractionated stereotactic radiotherapy (SFRT) for treatment of surgically complicated cavernous. For symptomatic cavernous malformations demonstrating anatomical position that may increase risk of surgical excision, so that SFRT is effective and safe method to control lesion size and improve visual function, but authors had not results of this therapy ${ }^{4}$.

\section{CONCLUSION}

The transnasal endoscopic resection of intra orbital tumors is feasible and may offer some advantages when compared to traditional approaches. This surgical treatment of orbital cavernous hemangioma is safe and effective.

Our young patient has optimal visual acuity of the affected right eye, after this surgical treatment of orbital hemangioma. 
Surgical treatment of symptomatic orbital cavernomas is reversible, so that the cosmetic results are the important parameters to evaluate the clinical outcome.

\section{RefERENCES}

1. Arora V,Prat MC, Kazim M.Acute presentation of cavernous hemangioma of the orbit. Orbit. 2011;30(4):195-7.

2. Friberg TR, Grove AS Jr. Choroidal folds and refractive errors associated with orbital tumors. An analysis. Arch Ophthalmol. 1983;101(4):598-603.

3. Wiegand S, Zimmermann AP, Eivazi B, Sesterhenn AM, Sekundo W, Bien S, et al. Analysis of clinically suspected orbital cavernomas. Br J Ophthalmol.

4. Rootman DB, Rootman J, Gregory S, Feldman KA, Ma R. Stereotactic fractionated radiotherapy for cavernous venous malformations (hemangioma) of the orbit. Ophthal Plast Reconstr Surg. 2012;28(2):96102.

5. Bouguila J, Yacoub K, Bouguila H, Neji NB, Sahtout S, Besbes G. [Intraorbital cavernous hemangioma]. Rev Stomatol Chir Maxillofac. 2008;109(5):312-5. French.
6. Bertelmann E, Hartmann C, Minko N. [Intraorbital cavernous hemangiomas: symptoms, diagnostics and surgical approaches]. Klin Monbl Augenheilkd. 2011;228(1):49-53. German.

7. Cophignon J, d'Hermies F, Civit T. [Vascular tumors of the orbit]. Neurochirurgie. 2010;56(2-3):197-212. French.

8. Yoshimura K, Kubo S, Yoneda H, Hasegawa H, Tominaga S, Yoshimine T. Removal of a cavernous hemangioma in the orbital apex via the endoscopic transnasal approach: a case report. Minim Invasive Neurosurg. 2010;53(2):77-9.

9. Stamm A, Nogueira JF. Orbital cavernous hemangioma: transnasal endoscopic management. Otolaryngol Head Neck Surg. 2009;141(6):794-5. 2010;94(12):1653-6.

10. Boari N, Gagliardi F, Castellazzi P, Mortini P. Surgical treatment of orbital cavernomas: clinical and functional outcome in a series of 20 patients. Acta Neurochir (Wien). 2011;153(3):491-8. Review.

Corresponding author:

Mirjana A. Janicijevic-Petrovic

Clinic of Ophthalmology, Clinical Centre in Kragujevac,

Zmaj Jovina 30, 34000 Kragujevac, Serbia

Mob: +38166013691 - Fax: +38134370073

E-mail:mira.andreja@yahoo.com 